\title{
Representaciones del cambio lingüístico en Chile durante el siglo XIX: ¿Progreso o decadencia?*
}

\section{Darío Rojas ${ }^{* *}$}

\section{Resumen}

En el Chile del siglo XIX, la lengua española era un asunto de interés político, por su rol fundamental en el proyecto de formación del Estado-nación independiente. De entre las facetas del lenguaje que ocuparon la atención de los intelectuales de esta época, nos enfocamos en el problema del cambio lingüístico, estrechamente vinculado con el del cambio social y cultural en general. Mediante el análisis de los discursos metalingüísticos que circularon en este periodo, y especialmente en la segunda mitad del siglo, mostramos que la valoración del cambio lingüístico en este contexto dependía de si se lo percibía como inocuo o como amenazante respecto de la unidad lingüística del mundo hispanohablante. En el primer caso, dado que la unidad era un ideal del proyecto de Estado-nación, el cambio era mirado positivamente; en el segundo caso, era objeto de actitudes negativas.

Palabras clave: historia de las ideas lingüísticas, historiografía lingüística, ideología lingüística, política lingüística, lingüística en Chile.

\section{Representations of language change in 19th Century Chile: Progress or decay?}

\begin{abstract}
In $19^{\text {th }}$-century Chile, Spanish language became a political issue, because of its role in the building of the independent nation-state. Among the many linguistic problems that attracted the attention of Chilean intellectuals from this period, we focus on the problem of language change. This problem had a close relation with that of social and cultural change. By means of analysis of metalinguistic discourses from this period (especially from the second half of the century), we argue that language change was perceived positively only if it was felt as a threat to linguistic unity, in which case it was equivalent to decay. Otherwise, it was linked to progress.
\end{abstract}

Keywords: history of linguistic ideas, linguistic historiography, language ideology, language policy, linguistics in Chile.

\footnotetext{
El presente trabajo está adscrito al proyecto FONDECYT-Regular 1150127 (CONICYT, Chile), del cual el autor es Investigador Responsable, y corresponde a una versión ampliada y revisada de una presentación del mismo título leída en el Coloquio de Lingüistica Histórica celebrado en la Pontificia Universidad Católica de Chile los días 13 y 14 de octubre de 2015.

** Chileno, Doctor en Filosofía y Letras (U. de Valladolid), Universidad de Chile, Facultad de Filosofía y Humanidades, Departamento de Lingüística. darioroj@uchile.cl
} 


\section{Introducción: ideologías lingüísticas e historia de la lengua}

La historiografía de las variedades chilenas de la lengua española se ha enfocado preferentemente en el periodo colonial (Cartagena, 2002; Contreras, 1995, 1998, 2000, 2004, 2005, 2007; Kordić, 2000-2001, 2011; Matus, 1998-1999; Matus, Dargham y Samaniego, 1992; Rojas, 2011; San Martín, 2006; entre otros). El tema no puede considerarse agotado, en absoluto, pero al menos contamos con buenos fundamentos para hacer algunas generalizaciones, tales como la de que los rasgos meridionales o "atlánticos" característicos de buena parte de las variedades americanas del español, entre ellos el seseo o el debilitamiento de consonantes implosivas, muestran una firme tenacidad histórica en el dialecto chileno y se encuentran ya asentados al finalizar la Colonia.

Por otro lado, lamentablemente no contamos todavía con fundamentos tan seguros para hacer generalizaciones sobre el periodo de la Independencia en la historia de los hispanohablantes chilenos. A pesar de que ya contamos con un puñado de investigaciones sobre este periodo (Avilés y Rojas, 2015; Frago, 2010a, 2010b; Matus, 1991; Rojas y Avilés, 2016), los estudios descriptivos todavía son escasos, y no precisamente por falta de documentación. A pesar de lo anterior, algunas de las investigaciones sobre la parte tardía de la Colonia aventuran hipótesis sobre las dinámicas de cambio lingüístico que pudieron haber caracterizado la época independiente, marcada por "el inicio del desarrollo del proceso de estandarización de la lengua española en Chile" (Matus et al., 1992, p. 562). Para Cartagena (2002), este habría comenzado en la segunda mitad del XVIII, pero transcurriría fundamentalmente entre 1842 y 1938.

Si aceptamos que la estandarización es uno de los procesos centrales del periodo independiente chileno, vale la pena considerar la totalidad de las diversas facetas asociadas a este tipo de proceso sociolingüístico, entre las cuales me interesa particularmente su dimensión ideológica, sicosocial y política. Es sabido que la selección de variantes lingüísticas y su elevación a la condición de estándar no tienen que ver con sus propiedades intrínsecas, sino más bien con su indicialidad respecto del poder y de las jerarquías sociales, es decir, "su capacidad para señalar elementos del contexto de la enunciación, indicar identidades sociales y construir relaciones entre los interlocutores" (Del Valle y Meirinho, 2016, p. 625). En esta perspectiva, el estudio de la estandarización lingüística 
"is less about language itself as function and structure, than it is about ideologies and hegemonies about languguage" (Inoue, 2006, p. 121). Los estudios de ideologías lingüísticas (cf. Del Valle y Meirinho, 2016) han mostrado que estos sistemas de representaciones situados socialmente se conforman, reproducen y transforman a través de los discursos, de manera que, finalmente, una parte importante del estudio de la estandarización lingüística en cualquier contexto histórico consiste en el estudio de los discursos acerca de la lengua, debidamente contextualizados en su marco histórico, político y cultural.

Este es evidentemente también el caso de la estandarización en el Chile hispanohablante del siglo XIX. Precisamente, es el periodo en que emerge una abundante cantidad de discursos acerca de la lengua española, cosa que raramente se observa en Chile en los siglos anteriores. Es cierto que los discursos metalingüísticos tienen importancia descriptiva para el estudio de la historia de la lengua española en Chile, pues la prescripción implica exhibir' ${ }^{1}$ Pero más allá de esta veta descriptiva de los documentos metalingüísticos, nos interesa destacar la importancia que tienen en sí mismos los discursos normativos acerca de la lengua española y las ideologías acerca del lenguaje asociadas a ellos, que eclosionaron y circularon durante el siglo XIX en Chile. El estudio de estos discursos nos permite acercarnos a comprender las motivaciones extralingüísticas (políticas, económicas, etc.) que tuvieron los actores sociales que intervinieron como agentes de estandarización lingüística.

Un aspecto específico de los discursos sobre la lengua del siglo XIX chileno que todavía no ha sido estudiado con detalle es la concepción y valoración del cambio lingüístico que les subyace. Nos parece especialmente interesante abordar este problema específico, pues se puede sospechar que este se imbrica, en el imaginario de los intelectuales chilenos de la época, con el problema más general del cambio (social, político, etc.), central en el contexto de formación y consolidación del Estadonación independiente ${ }^{2}$. Es decir, se trataría de un objeto lingüístico-ideo-

\footnotetext{
1 Por ejemplo, Andrés Bello ([1833-1834] 2013, p.6o), al censurar la pronunciación [us'te] del ítem léxico usted, está indirectamente dejando constancia de que el debilitamiento de /d/ implosiva tenía un amplio uso en la comunidad de hispanohablantes chilenos de la primera mitad del XIX. Asimismo, el autor anónimo del catálogo de 1843 (Ferreccio, 1979, p. 48), al proscribir la forma de imperativo decí (de decir), está revelando que el voseo verbal en imperativo estaba muy vivo en Chile por esos años, a diferencia de lo que sucede hoy.

2 Jaksić (2015) interpreta en tal sentido el interés de Bello por la historia de las lenguas romances, y del castellano en particular, tal como se manifestó en sus trabajos sobre el Poema de Mio Cid:

Del mismo modo que había logrado una comprensión del desarrollo histórico a través
} 
lógico que permite, precisamente, asomarnos a la dimensión política de las representaciones que se construyen durante la estandarización. Con el presente trabajo, mediante el examen de documentos metalingüísticos de la época, nos proponemos contribuir a esclarecer dicho problema.

\section{Cambio lingüístico y unidad del idioma en la primera mitad del XIX: Andrés Bello}

Debemos dejar en claro desde un comienzo que el cambio lingüístico en realidad no suele tematizarse como tal en los discursos metalingüísticos del siglo XIX chileno. Es un asunto más bien latente y subyacente a una de las preocupaciones lingüísticas fundamentales de las élites hispanohablantes de la época de las Independencias: la unidad de la lengua española. Quizá el que no se hable de cambio lingüistico en estos discursos obedece a que el estudio del lenguaje en Chile, durante este siglo, se encuentra en una etapa previa a la profesionalización y a la aparición de una lingüistica tal como la entendemos hoy, que precisamente durante ese mismo siglo desarrollaba sus principales contribuciones al entendimiento del desarrollo histórico del lenguaje ${ }^{3}$. Por lo mismo, puede decirse que en estos autores el concepto de cambio lingüistico se encuentra en un estado preteórico.

José del Valle (comunicación personal) propone que, en la América hispanohablante del XIX, el cambio (manifestado fundamentalmente en su faceta de la innovación) tenderá a ser valorado positiva o negativamente de acuerdo con si se lo entendía como factor de convergencia

del estudio de la lengua, Bello estaba seguro de que el idioma podía servir de guía para la posteridad independiente. La historia de la lengua era una historia de cambios y variaciones, pero era también una historia de contactos, de armonía, belleza y unidad. La cohesión y longevidad de los idiomas superaba a la de los sistemas políticos, y servía así de modelo de continuidad y estabilidad susceptible, no obstante, de cambio dentro del orden. La clave residía en la capacidad del lenguaje de absorber el cambio a partir de una matriz sólida. (p.189).

Es decir, se trata de un interés que trasciende el problema meramente lingüístico, y que alcanza a la vida política y social.

3 La lingüística como disciplina científica moderna arribó a Chile recién en 1890, con los alemanes Federico Hanssen y Rodolfo Lenz, contratados por el Instituto Pedagógico de la Universidad de Chile. Ambos se habían formado en la escuela de los neogramáticos de Leipzig, que representaba el punto culminante de la lingüística histórica que se había desarrollado principalmente en Alemania desde comienzos del XIX, y que, por supuesto, ponía en un lugar central de la teoría lingüística el problema del cambio lingüístico. Sin embargo, en 1874, Francisco Solano Astaburuaga había publicado en la revista Sud-América un texto de divulgación llamado "Idea de la lingüística o ciencia del lenguaje", en donde daba a conocer ideas de lingüistas como Bopp, Grimm, los hermanos Schlegel y Whitney. Dicho texto puede considerarse, hasta donde sabemos, la primera noticia que circuló en Chile, con bastante atraso por cierto, de la novedosamente llamada lingüística. 
(unidad) o de divergencia (fragmentación) lingüística. Esta idea parece muy razonable como hipótesis de trabajo para abordar el caso chileno, porque en este ambiente cultural, y especialmente durante la segunda mitad del siglo (Rojas 2015), predominó la ideología de la lengua estándar (Milroy, 2007), imponiéndose hegemónicamente por sobre la ideología de corte romántico representada por Sarmiento ${ }^{4}$. La ideología de la lengua estándar, precisamente, pone en un lugar central el ideal de la unidad del idioma.

La ideología de la lengua estándar corresponde a un sistema de creencias (generador a su vez de actitudes fuertemente prescriptivas y naturalizadas como sentido común en la mayoría de las sociedades modernas) que opera reductivamente sobre el objeto discursivo "la lengua", identificándola con una única forma legítima, el estándar, caracterizado por propiedades como la corrección y asociado al prestigio social manifiesto, y que funciona como medida de calidad para toda conducta lingüística. En esta ideología lingüística, lo distinto al estándar no es variación, sino error, incompetencia, incorrección, en fin, simplemente no es parte de la lengua en cuestión.

La ideología del estándar tiene como uno de sus componentes fundamentales el mito de la homogeneidad lingüística, que se basa en "the assumption that a language can reach perfection and that it can be completely homogeneous" (Watts, 2012, p. 595); perfección, en este contexto, se entiende como 'pureza, inmutabilidad, consistencia lógica total, etc.' La estandarización, en el fondo, se basa en un ideal inalcanzable: la imposición de uniformidad sobre una clase de objetos (las conductas lingüísticas) que por naturaleza son variables. Justamente por esa razón el ideal de la homogeneidad tiene condición de mito.

De modo congruente con dicha ideología lingüística, la homogeneidad, la estandarización de la lengua española, fue sentida por las élites gobernantes hispanoamericanas del XIX como una necesidad para el

4 El pensamiento romántico del político, periodista y educador argentino Domingo Faustino Sarmiento (1811-1888) tuvo una figuración importante en los debates lingüísticos chilenos de la primera mitad del siglo XIX. Durante sus exilios en Chile (1831-1836 y 1840-1851) fue el principal antagonista intelectual de Andrés Bello en el ámbito de las ideologías lingüísticas (Velleman, 2002). Sin embargo, en Chile la concepción romántica de la lengua española (separatismo lingüístico y cultural, lengua como símbolo de identidad, autenticidad y legitimidad del habla popular, etc.) ocupó un lugar marginal frente a la hegemonía de la ideología del estándar. Huisa (2014) hace notar, con mucha razón, que la historiografía del pensamiento lingüístico de este periodo a veces supone incorrectamente que el romanticismo argentino y su fuerte presencia en el entorno cultural de aquel país tiene paralelos en toda Hispanoamérica, cosa que no se cumple al menos en los casos del Perú y de Chile. 
funcionamiento apropiado de las nuevas naciones independientes. De tal manera, la percepción de la amenaza de la fragmentación conllevaba preguntarse qué medidas podían o debían tomarse para evitarla y quiénes debían estar a cargo de ellas ${ }^{5}$.

En el contexto chileno, es Andrés Bello (1781-1865) el primero que pone énfasis en el valor comunicativo y político de la unidad lingüística. Este político nacido en Venezuela, abogado, escritor y filólogo, llegó a Chile en 1829 y desempeñó un papel fundamental en la formación de la República chilena (Jaksić, 2010). En una declaración muy citada del prólogo de su Gramática, Bello expresó que promover la unidad de la lengua española permitiría contar con "un medio providencial de comunicación y un vínculo de fraternidad entre las varias naciones de origen español derramadas sobre los dos continentes" ([1847] 2013, p. 48). Los románticos como Sarmiento, en cambio, planteaban abiertamente una escisión lingüístico-ideológica respecto de España, lo que conllevaba valorizar la diferencia idiomática con la metrópoli y de esta manera reforzar la autonomía identitaria de las nuevas naciones.

En Chile, fueron Bello y sus epígonos, a quienes podemos llamar racionalistas (siguiendo la tipología modelos culturales de la estandarización propuesta por Geeraerts (2016)), quienes triunfaron en esta pugna ideológica, principalmente gracias a su influencia política y cultural (recuérdese que Bello, además de oficial ministerial y senador, fue rector fundador de la Universidad de Chile, cargo que conservó hasta su muerte), y, creemos, también, gracias a que su proyecto lingüístico-cultural era muy afín a la pulsión por el orden y la estabilidad que marcó la política de la República Conservadora desde 1830 hasta 1860 aproximadamente. Por esta razón, a los racionalistas chilenos les fue posible aplicar sus ideas mediante una política lingüística de tipo prescriptivo apoyada de manera oficial por el Gobierno chileno y materializada en numerosos instrumentos lingüísticos (Auroux, 2009) o escrituras disciplinarias (González-Stephan, 2004), des-

5 Las intervenciones polémicas sobre este asunto, sostenidas por el colombiano Rufino José Cuervo y el español Juan Valera entre 1899 y 1903, resultan de especial relevancia para comprender el problema (Del Valle, 2002). Cuervo afirmaba (basado en los datos de la ciencia lingüística del momento) que la fragmentación era inevitable, y que los hispanoamericanos estaban prontos a quedar separados por el lenguaje, tal como había pasado con los latinohablantes al caer el Imperio. Valera, en cambio, sostenía que en realidad la lengua (y la "raza" española) era una sola y que su identidad persistiría a pesar de posibles factores centrífugos. Sin embargo, como destaca Del Valle (2002), en Cuervo convergen ciencia y política a través de la instrumentación de la ciencia del lenguaje en favor de la unidad idiomática, es decir, a través de una propuesta planificación lingüística orientada a lograr que el cambio desembocara en convergencia. Cuervo pensaba que, a pesar de la demostrable inevitabilidad del cambio y la fragmentación, era su responsabilidad, como intelectual hispanoamericano, trabajar en pos de la unidad. 
tinadas a la corrección de los hábitos idiomáticos que, según se creía, iban en detrimento de la unidad de la lengua española en América. Los diccionarios de provincialismos chilenos, por ejemplo, según hemos explicado en algún trabajo anterior (Rojas, 2010), pueden ser interpretados como los mecanismos discursivos a través de los cuales se daba forma concreta al proceso de estandarización en nuestro país, sobre todo en cuanto a los procesos de selección y codificación, operando como macroactos de habla directivos destinados a modificar las conductas lingüísticas de los hispanohablantes chilenos para hacerlas coincidir con el estándar que garantizaba la preservación de la unidad.

La unidad de la lengua era importante para los racionalistas porque evitaría una situación indeseada: una posible fragmentación dialectal de la lengua española en Hispanoamérica, análoga a la experimentada por el latín al fragmentarse el Imperio romano e iniciarse una era que las naciones europeas modernas veían con malos ojos por su "oscuridad" cultural, y que los americanos no querían ver replicada, por lo tanto, en sus nuevas naciones. Pero la variación lingüística también era vista por Bello, concretamente, como un obstáculo práctico para el progreso y los asuntos cívicos de las nuevas naciones.

[La avenida de neologismos de construcción], alterando la estructura del idioma, tiende a convertirlo en una multitud de dialectos irregulares, licenciosos, bárbaros; embriones de idiomas futuros que durante una larga elaboración reproducirían en América lo que fue la Europa en el tenebroso período de la corrupción del latín. Chile, el Perú, Buenos Aires, México, hablarían cada uno su lengua, o por mejor decir, varias lenguas, como sucede en España, Italia y Francia, donde dominan tres idiomas provinciales, pero viven a su lado otros varios, oponiendo estorbos a la difusión de las luces, a la ejecución de las leyes, a la administración del Estado, a la unidad nacional. (Bello [1847] 2013, p. 48-49; negritas del autor).

El modelo ideal de español unificado, el "español correcto" de los racionalistas chilenos, que funcionaba como foco de la convergencia, tenía un marcado sesgo propeninsular. Como ha mostrado Moré (2014, p. 93-103), a pesar de que Bello parece a veces valorar positivamente la particularidad lingüística americana ("Chile y Venezuela tienen tanto derecho como Aragón y Andalucía para que se toleren sus accidentales divergencias" (Bello, [1847] 2013, p. 49)), también, revela en varias otras 
partes de sus escritos su preferencia por la norma peninsular ("los que se cuidan de evitar todo resabio de vulgarismo en su pronunciación [...] distinguirán también la $s$ de la $z$ o $c$ " (Bello, [1833-1834] 2013, p. 78)).

Es decir, se trataba de construir unidad idiomática en torno a un modelo que, para los chilenos, tenía carácter exógeno, pero que tenía la ventaja de que se vinculaba con una larga tradición cultural que para sujetos como Bello garantizaba orden y estabilidad debido a la abundancia de modelos (Jaksić, 1999). En la medida en que las innovaciones en el lenguaje corrieran por los cauces de esta tradición, entonces, el cambio no era sentido como una amenaza a la unidad, pues la tradición era en teoría compartida por todos los hispanohablantes, sino, por el contrario, podía incluso convertirse en equivalente de progreso ${ }^{6}$.

\section{La segunda mitad del XIX: los epígonos de Bello}

Los discursos lingüístico-ideológicos de autores de diccionarios, gramáticas o ensayos metalingüísticos de la segunda mitad del XIX, miembros de la élite cultural hispanohablante chilena (tales como Valentín Gormaz, Ramón Sotomayor, Zorobabel Rodríguez, Fidelis del Solar, Fernando Paulsen, Aníbal Echeverría y Reyes, entre otros), muestran un importante grado de coherencia grupal en sus ideas y actitudes acerca de la lengua española, que permite caracterizarlos como una comunidad discursiva (Watts, 2008) chilena articulada en torno al lenguaje como objeto de reflexión, en el sentido de que compartían intereses (por ejemplo, la educación lingüística), metas (por ejemplo, la unidad del idioma) y creencias.

Esta comunidad discursiva instancia una versión históricamente circunstanciada de la ideología de la lengua estándar, afín a los modelos racionalistas de la estandarización lingüística, y de impronta culturalmente conservadora. Se puede ver en sus discursos, nuevamente, una actitud en principio (pero no necesariamente) negativa hacia el cambio lingüístico, congruente con la condición de epígonos de Bello que ostentaban todos estos personajes. En principio negativa, decimos, porque si

6 "Pero no es un purismo supersticioso lo que me atrevo a recomendarles. El adelantamiento prodigioso de todas las ciencias y las artes, la difusión de la cultura intelectual y las revoluciones políticas, piden cada día nuevos signos para expresar ideas nuevas, y la introducción de vocablos flamantes, tomados de lenguas antiguas y extranjeras, ha dejado ya de ofendernos, cuando no es manifiestamente innecesaria, o cuando no descubre la afectación y mal gusto de los que piensan engalanar así lo que escriben" (Bello, [1847] 2013, p.48). 
una innovación de los hablantes chilenos cumplía con ciertos requisitos (los "cauces" a los que nos referimos antes), estos autores consideraban que era digna de integrarse al estándar, es decir, podía pasar a ser objeto de valoración positiva.

Vamos a exponer ahora algunos ejemplos de cómo se manifiesta este patrón lingüístico-ideológico en algunos de los discursos metalingüísticos de los autores de este grupo.

Valentín Gormaz (1860), en sus Correcciones lexigráficas sobre la lengua castellana, señala, entre varios "defectos" que caracterizan al dialecto chileno, el usar variantes que "no existen", es decir, innovaciones que exceden los límites impuestos por el estándar, que fija los límites del ser de la lengua. Además de muchas innovaciones léxicas que "no existen" por haber ya una expresión equivalente en el estándar, Gormaz censura variantes morfológicas (abanderarse por abanderizarse) o de pronunciación (brigadiel por brigadier). Un gran número de las variantes de pronunciación consideradas por Gormaz como "inexistentes" se explican por tendencias de pronunciación características del dialecto chileno en cuanto variedad del español atlántico: debilitamiento de /s/ implosiva (arriejar por arriesgar o refalar por resbalar), neutralización de líquidas implosivas (arcancía por alcancía), seseo (fresada por frazada), yeísmo (rayo por rallo) o debilitamiento de /d/ (grea por greda).

La declaración de "inexistencia” por parte de Gormaz puede entenderse mejor sobre el trasfondo de la ideología de la lengua estándar, de acuerdo con la cual, como ya explicamos, la actuación lingüística "correcta" se reduce al modelo ideal de lengua, de modo que las innovaciones surgidas en variedades regionales o sociales son catalogadas como error o producto de una mera falta de competencia idiomática: es decir, al "no saber hablar". La innovación, en este caso, queda casi condenada de antemano a una valoración negativa, por considerársela equivalente a error, a confusión, a equivocación, a desvío de respecto de una conducta esperada, desvío que obstaculiza la unidad.

El discurso “Formación del Diccionario Hispano-americano”, de Ramón Sotomayor (1866), toca un aspecto muy concreto de la ideología lingüística del XIX hispanoamericano: el papel que asignaba esta comunidad al diccionario en el proceso de estandarización. La intención de Sotomayor queda clara al comenzar su discurso: proponer la creación de un diccionario de lengua española hecho por hispanoamericanos, con el propósito de "evitar la degeneración del idioma castellano en las diversas 
secciones de la América antes española" (p. 665). Para este autor es de especial necesidad levantar esta autoridad lingüística en Hispanoamérica, pues en este contexto contribuyen en particular a dicha "degeneración": 1) la idea generalizada de desespañolizar América (asociada, según nuestro autor, a la adopción de extranjerismos léxicos y el calco del estilo literario extranjero), 2) la inmigración extranjera, fuente de disrupción de "la unidad i la fisonomía clásica de nuestra lengua, inundándola de elementos que no ha menester i que, con conservar su forma estrambótica, la van desfigurando caprichosamente" (p. 667) el mal manejo del idioma por parte de los periodistas, quienes, en la urgencia exigida por la contigencia noticiosa, escriben con poco cuidado.

Para Sotomayor, el modelo idiomático que debe servir como foco de la convergencia es la lengua literaria. Fijar el carácter propio del idioma, por otra parte, para él igual que para Bello, contribuye a darle la capacidad de ir a la par del "progreso de las ideas i [...] las novedades que ocurren en la vida social" (Sotomayor, 1866, p. 669), capacidad necesaria, pues "si el lenguaje no es mas que el conjunto de signos para manifestar las ideas, preciso es que su horizonte se estienda al par del pensamiento" (p. 669).

Esta consideración le abre espacio para plantear el problema del neologismo, que es un tipo específico de innovación que concentra gran parte de la atención de estas reflexiones (indirectas) acerca del cambio lingüístico por parte de los intelectuales chilenos de la segunda parte del siglo. Sotomayor considera que el neologismo es prerrogativa de los escritores y que la introducción de nuevos vocablos debe ir por la senda de la necesidad denominativa y el ajuste a una especie de "genio" del idioma. La lengua castellana para Sotomayor debe ser selectiva precisamente por haber ya alcanzado un alto grado de cultivo literario (es "un idioma ya formado"), de modo que "es bueno juntar la puerta, aunque sin condenarla" (Sotomayor, 1866, p.670). El autor considera que en realidad muchas de las innovaciones léxicas se deben a simple desconocimiento de la tradición del idioma, y estas innovaciones por tanto son prescindibles.

En el Diccionario de chilenismos de Zorobabel Rodríguez (1875), se pueden apreciar claramente, a lo largo del cerca de millar de entradas léxicas que lo conforman, los criterios utilizados comúnmente por los integrantes de esta comunidad discursiva para declarar aceptable una innovación lingüística propia del castellano chileno. A modo de ejemplo, Rodríguez tolera la existencia de provincialismos en el nivel culto si estos aluden a un referente o concepto para cuya denominación la len- 
gua castellana no posee ningún equivalente exacto. Lo anterior se refleja claramente en la monografía sobre pirca. El dato que sirve a Rodríguez para concluir que es un uso aceptable consiste en que existe una laguna denominativa en la lengua castellana con respecto a este referente (un tipo de pared de piedras con barro), ya que para llamar a este tipo específico de pared no existe otro equivalente exacto. Consecuentemente, un provincialismo que satisfaga dicho vacío, como pirca, será considerado por el autor como una "voz útil", pues su adición al caudal léxico español responde a una necesidad denominativa.

Además de préstamos léxicos provenientes de lenguas indígenas, como pirca, también hay innovaciones americanas de raigambre hispánica que merecen, en opinión de Rodríguez, incorporarse a la lengua ejemplar (el resalte con negritas es nuestro):

DICTAMINAR.

El señor Salvá pone a esta voz la nota: "Provincialismo de la América Meridional, dar dictamen”, aseveración confirmada por el silencio que acerca de ella guarda el Diccionario de la Academia. De desear sería que se procediese cuanto antes a otorgarle carta de ciudadanía; pues es lo cierto que si se eliminase no quedaría, para expresar la idea, más arbitrio que recurrir al circunloquio dar dictamen, y sabido es que nunca debe desterrarse un vocablo correctamente formado, aunque sea nuevo, para servirse de circunloquios o de frases.

EMPASTAR, EMPASTADOR.

Significa el primero encuadernar libros en pasta, y el segundo la persona que tiene por oficio el de encuadernarlos así. Son provincialismos de la América Meridional, segun Salvá; pero mui dignos de conservarse porque, además de bien formados, no tienen equivalentes castizos.

Frente a los testimonios lexicográficos y el carácter provincial de la voz, cobra mayor importancia para Rodríguez la satisfacción de una necesidad de denominación resuelta por el vocablo en cuestión. Así, en el primer caso, a pesar de que dictaminar sea considerado un provincialismo, la alternativa es un circunloquio, lo que va en contra de la economía de expresión, que es una virtud para Rodríguez. Es importante notar que a propósito de dictaminar nuestro autor hable de "otorgar carta de ciudadanía" a un vocablo, frase con la cual activa una metáfora concep- 
tual compleja según la cual la lengua española es un Estado-nación y los vocablos son los ciudadanos de la nación, además de haber un procedimiento legal de nacionalización que permite a un vocablo "no ciudadano" convertirse en ciudadano, por los servicios que ofrece. Es una metáfora interesante porque alude a ámbitos culturales de gran significancia para los intelectuales chilenos del siglo XIX, como son la nación y el orden legal que configura al Estado.

Incluso un extranjerismo, que Rodríguez en principio rechazaría violentamente, puede ser aceptado en el estándar si llena un vacío denominativo. Tal es el caso de expreso, el que, aunque sea "chilenismo tomado del inglés", es considerado por Rodríguez "útil” por su doble función de sustantivo referido a una casa de comercio que transporta encomiendas y de adjetivo aplicado a trenes que hacen su viaje de manera más rápida que los comunes.

Los ejemplos anteriores de Gormaz, Sotomayor y Rodríguez ilustran la tónica general de los autores de esta comunidad discursiva conformada por los epígonos de Bello de la segunda parte del siglo XIX. Si hubiera que escoger una imagen general que represente la visión que tenían estos sujetos del devenir histórico del lenguaje en el marco de las naciones americanas, más allá de creencias particulares, aquella imagen sería la del progreso sometido a un orden, la del cambio sometido a principios reguladores. Varios de estos intelectuales se distanciaban conscientemente del purismo extremo que rechaza toda innovación, por considerarlo poco apto para el contexto de la consolidación del Estado chileno. En cambio, abrazaban la posibilidad de incorporar innovaciones, pero siempre y cuando estas cumplieran con ciertos requisitos de calidad, que contribuirían a mantener la lengua dentro del cauce impuesto por lo que era considerado como una especie de "genio del idioma" (aunque varios de nuestros autores jamás usan este concepto).

La posibilidad de admitir innovaciones en el idioma, por otra parte, aseguraba para la élite hispanohablante chilena un espacio de participación en el marco más general de la política y planificación lingüísticas del conjunto de naciones que compartían esta lengua, incluida España. En el texto programático de Sotomayor, sobre todo, se puede apreciar el deseo de participación que motiva a los hispanohablantes chilenos a intervenir en la reflexión metalingüística del XIX. No debe perderse de vista, de cualquier modo, que este deseo de inspiración revindicacionista es muy distinto del separatismo propugnado por románticos como Sarmiento 
durante la primera mitad del siglo. Los autores de la segunda mitad del siglo se sienten parte de una comunidad transnacional, con la cual quieren activamente compartir lo que sentían como un patrimonio común, a saber, la lengua castellana y sus monumentos literarios y culturales. Es decir, eran prototípicamente racionalistas e hispanistas en cuanto a la lengua. De ahí el empeño que ponen en la necesidad de difundir y acatar los principios que actúan como "filtros" para seleccionar unidades léxicas y otros rasgos lingüísticos con miras a integrarlos a un estándar supranacional. Sin embargo, los autores se atribuyen y reconocen un lugar subordinado o periférico (en relación con España) dentro del concierto glotopolítico internacional.

Lo que tienen de común los autores estudiados puede entenderse como una versión históricamente contextualizada de la ideología de la lengua estándar, que se manifiesta acá al considerarse como parámetro de corrección un objeto ideal platónico hacia el cual deben tender las conductas idiomáticas para ser consideradas socialmente válidas. El modelo ideal es objetivado a través de una serie de principios que reflejan el "genio del idioma", así como a través de los códigos de la Academia española. Son estos los parámetros, entonces, que orientan la conducta lingüística deseable, la cual, por otra parte, corresponde con la variante propia del grupo que goza de mayor nivel socioeconómico y de mayor prestigio social, el habla de los cultos, grupo al cual pertenecen los autores que hemos estudiado. Finalmente, este modelo (un español culto internacional, de raigambre literaria y castellanizante) es erigido de manera exclusiva como el único hablar legítimo. Los autores de nuestro corpus a menudo hablan de "la lengua", como si esta tuviera unos límites bien definidos que sirven para separar tajantemente entre las conductas que caen dentro de su espacio imaginario y las que no. Para estos intelectuales, "esta lengua de Estado se convierte en la norma teórica con que se miden objetivamente todas las prácticas lingüísticas" (Bourdieu, 2001, p.19), lo cual se refleja en el quisquilloso escrutinio al que son sometidas las variantes percibidas como innovaciones particulares de la comunidad hispanohablante chilena, alteradoras de la unidad.

Como ha destacado Huisa (2013), no puede obviarse que la reflexión metalingüística de la época, en Chile y en otros lugares de América, tiene por marco el proceso de formación del Estado y de la "invención de la nación". La instrumentalidad política, precisamente, es el sentido que tiene para nuestros autores preocuparse por el lenguaje. Y aquí política debe 
entenderse en un sentido amplio, en que ocupa un lugar fundamental la educación. Varios de nuestros autores conciben sus propias obras como tareas al mismo tiempo patrióticas y educativas. Las formas expositivas que adoptan sus discursos, entonces, se relacionan con la utilidad que se les asignaba.

Coincidimos con Huisa (2013) en que, en lugar de la oposición historiográfica tradicional entre conservadores y liberales, resulta más productivo para el caso que estudiamos considerar el republicanismo ${ }^{7}$ como paradigma explicativo. La mayoría de los miembros de la comunidad discursiva que caracterizamos tuvo adscripción política al Partido Conservador, pero hay que tener en cuenta que el conservadurismo chileno igualmente funciona dentro de esquemas republicanistas. En efecto, la inspiración del ideario liberal resulta clave, por ejemplo, para entender la prominencia del ideal educativo en la reflexión metalingüística. Y esto, como destaca Arnoux (2008, p.9 y ss.), tiene que ver con el deseo de formar ciudadanos funcionales a los intereses del Estado y el progreso de la nación.

El lema "Lengua oficial y unidad política” (Bourdieu, 2001, p.18) sintetiza muy bien la relación entre lenguaje y política que subyace a los discursos de esta época. La unidad idiomática, deseada y garantizada por la ideología de la lengua estándar, tiene directa relación con la unidad política. La estandarización lingüística, proceso al cual respondían los textos lexicográficos, gramaticales y ortográficos que tanto abundaron en la segunda parte del Chile decimonónico, se enmarca en la homogeneización del Estado. Las palabras del sociólogo francés, nuevamente, sirven muy bien para explicar lo que sucede en el caso chileno:

La lengua oficial se ha constituido vinculada al Estado [...]. Es en el proceso de constitución del Estado cuando se crean las condiciones de la creación de un mercado lingüístico unificado y dominado por la lengua oficial: obligatorio en las ocasiones oficiales y en los espacios oficiales (escuela, administraciones públicas, instituciones políticas, etc.), esta lengua de Estado se convierte en la norma teórica con que se miden objetivamente todas las prácticas lingüísticas. Se supone que nadie ignora la

7 "Este paradigma identifica en la realidad de los hechos un deseo consciente por parte de las elites criollas en todo el continente de establecer un tipo determinado de gobierno a partir de pautas claras identificadas con el liberalismo europeo y sobre la base de una indispensable sociedad de ciudadanos" (Huisa, 2013, p.287). 
ley lingüística, que tiene su cuerpo de juristas, los gramáticos, y sus agentes de imposición y control, los maestros de enseñanza primaria [...]. Para que una forma de expresión entre otras (en el caso de bilingüismo una lengua, un uso de la lengua en el caso de la sociedad dividida en clases) se imponga como la única legítima, es preciso que el mercado lingüístico se unifique y que los diferentes dialectos de clase [...] se midan en la práctica por el rasero de la lengua o según uso legítimo [sic]. La integración en la misma "comunidad lingüística", que es un producto de la dominación política constantemente reproducida por instituciones capaces de imponer el reconocimiento universal de la lengua dominante, constituye la condición de la instauración de relaciones de dominación lingüística (Bourdieu, 2001, p.19-20).

Hay que volver a Andrés Bello para comprender cabalmente el sentido de estos discursos metalingüísticos en cuanto manifestaciones de proyectos de política cultural. Las creencias y actitudes acerca del lenguaje que hemos identificado, a pesar de la inspiración liberal, son culturalmente conservadoras. Es muy relevante el hecho de que una acción clave tanto para Bello como para sus epígonos autores era la de conservar, mantener, es decir, una remisión a la tradición. Los autores que estudiamos se sienten parte de una comunidad culta transnacional articulada, tanto en el nivel simbólico como en el nivel de las prácticas, en torno a la lengua culta literaria castellana. Por pertenecer a esta comunidad, disfrutan de los beneficios derivados de ella (prestigio social, por ejemplo), pero también asumen responsabilidades (las “tarea patriótica”), entre las cuales se encuentra el preservar la tradición (lo cual implica conocerla, es decir, ser culto), que constituye en gran medida el fundamento de legitimidad de la misma comunidad. De ahí la necesidad percibida de cultivar el idioma, para mantenerlo dentro de los cauces delineados por la tradición, a pesar de las novedades exigidas por el progreso.

Pues bien: Bello fue el gran conservador cultural de la época. Según la interpretación de Jaksić (2010), la ley (no solo entendida en términos legales) se convirtió para él en la única garantía de estabilidad dentro de un nuevo Estado independiente. Para comprender cómo funciona el imperio de la ley, Bello acudió a la tradición: los cantares de gesta de la Europa medieval, el derecho romano y su supervivencia en las tradiciones hispano-visigóticas, etc. La marcha del progreso debía ser estabilizada 
sobre fundamentos firmes que al parecer solo podían ser garantizados por un importante apego a la tradición. Gradualismo, más que transformación, era lo que deseaba Bello. El gramático chileno-venezolano aplicó fielmente estas ideas a su labor lingüística, y sus epígonos no hicieron sino continuar esta postura intelectual.

\section{Conclusión}

El cambio lingüístico, para los intelectuales chilenos del XIX, no implicaba por necesidad ni progreso ni decadencia, sino que dependía de sus posibles consecuencias para la unidad del idioma. Si el cambio quedaba encauzado dentro de los principios de aceptabilidad, si cumplía con las cualidades deseables determinadas por el perfil del modelo ideal de lengua, era concebido como progreso, en cuyo caso se entendía como inocuo para la conservación de la unidad idiomática. Por tanto, la actitud hacia este tipo de cambio era positiva. Por el contrario, si el cambio transgredía estos márgenes, la evaluación era negativa, pues se lo percibía como introductor de caos y como potencial amenaza a la unidad de la lengua.

Es decir, lo que importaba era la medida en que el cambio se daba dentro del orden, lo que no es sorprendente si se considera la importancia que este último concepto tuvo en la formación y consolidación del Estado independiente chileno, tanto en los discursos como en las prácticas de diversas esferas de la cultura y la vida cívica (Ruiz, 2015). En resumen, la diferencia radicaba en si el cambio era entendido como "progreso" o como "decadencia", para usar los términos del conocido trabajo de Aitchison (2004) que inspira el título de la presente comunicación.

\section{Bibliografía}

Aitchison, J. (2004). Language change: progress or decay? $3 .^{\mathrm{a}} \mathrm{ed}$. Cambridge: Cambridge University Press.

Arnoux, E. (2008). Los discursos sobre la nación y el lenguaje en la formación del Estado (Chile, 1842-1862). Estudio glotopolítico. Buenos Aires: Santiago Arcos.

Auroux, S. (2009). A revolução tecnológica da gramatização. Trad. de E. Puccinelli Orlandi, 2. ${ }^{\text {a }}$ ed. Campinas: Unicamp 
Avilés, T. y Rojas, D. (2015). Rasgos fónicos y morfológicos en cartas de hispanohablantes emigrados a la pampa salitrera chilena (18831937). Zeitschrift für Romanische Philologie, 131(3), 632-663.

Bello, A. ([1833-1834] 2013). Advertencias sobre el uso de la lengua castellana, dirigidas a los padres de familia, profesores de los colegios y maestros de escuela. En A. Bello, Gramática de la libertad. Textos sobre lengua y literatura, comps. I. Jaksic, F. Lolas \& A. Matus (pp. 59-82). Santiago: Universidad de Chile.

- ([1847] 2013). Prólogo de Gramática de la lengua castellana destinada al uso de los americanos. En Andrés Bello, Gramática de la libertad. Textos sobre lengua y literatura, comps. I. Jaksic, F. Lolas \& A. Matus (pp. 43-50). Santiago: Universidad de Chile.

Bourdieu, P. (2001). La producción y reproducción de la lengua legítima. En ¿Qué significa hablar? Economía de los intercambios lingüisticos, 3. ${ }^{\mathrm{a}}$ ed. (pp. 17-39). Madrid: Akal.

Cartagena, N. (2002). Apuntes para la historia del español en Chile. Santiago: Cuadernos de la Academia Chilena de la Lengua.

Contreras, M. (1995). El seseo como fenómeno de koinización en el Reino de Chile. En Actas del IV Congreso Internacional de «El Español de América», 7 al 11 de diciembre de 1992 (pp. 156-162). Santiago: Pontificia Universidad Católica de Chile.

- (1998). El español de Chile desde una perspectiva sociolingüística histórica. ALPHA, 14, 137-165.

. (200o). Criollismo lingüístico en el español de Chile del período colonial. Estudios Filológicos, 35, 41-59.

. (2004). El español de Chile en el período colonial. Fonética. Osorno: Universidad de Los Lagos.

. (2005). Ilegibilidad y cotidianeidad. Paleografía y colección diplomática de documentos chilenos del período colonial (1548-1651). Osorno: Universidad de Los Lagos.

. (2007). Un momento en la historia del español de Chile. Estudios Filológicos, 42, 59-77.

Del Valle, J. (2002). Historical linguistics and cultural history. The polemic between Rufino José Cuervo and Juan Valera. En J. del Valle \& L. Gabriel-Stheeman (eds.), The Battle over Spanish between 1800 and 200o. Language ideologies and Hispanic intellectuals (pp. 64-77). London \& New York: Routledge. 
Del Valle, J. y Meirinho-Guede, V. (2016). Ideologías lingüísticas. En J. Gutiérrez-Rexach (ed.), Enciclopedia de lingüística hispánica, vol. 2 (pp. 622-631). London \& New York: Routledge

Ferreccio, M. (1979). Las fuentes de la filología chilena. I. El catálogo anónimo de 1843. Atenea, 440, 39-59.

Frago, J. A. (2010a). El español de América en la Independencia. Santiago: Aguilar.

(2010b). Sobre el español de Chile: del período colonial al independiente. Boletín de Filología, 45(1), 103-126.

Geeraerts, D. (2016). Cultural models of linguistic standardization. Diacronia, 3, 1-21

González-Stephan, B. (2004). On citizenship: the grammatology of the body-politic. En A. del Sarto, A. Ríos y A. Trigo (eds.), The Latin American Cultural Theory Reader (pp. 384-405). Durham \& London: Duke University Press.

Gormaz, V. (1860). Correcciones lexigráficas sobre la lengua castellana en Chile. Valparaíso: Imprenta del Comercio.

Huisa, J. C. (2013). La impronta política en la primera lexicografía hispanoamericana: republicanismo y antirrepublicanismo. Lexis, 37(2), 269-303.

. (2014). Revisión crítica de la historiografía de las ideologías lingüísticas de Hispanoamérica. El caso de la lexicografía peruana decimonónica. En M. L. Calero et al. (eds), Métodos y resultados actuales en Historiografía de la Lingüística (pp. 391-398). Münster: Nodus.

Inoue, M. (2006). Standardization. En K. Brown (ed.), Encyclopedia of Language \& Linguistics, $2^{\mathrm{a}}$ ed., vol. 6 (pp. 121-127). Oxford: Elsevier.

Jaksić, I. (1999). La gramática de la emancipación. En G. Carrera Damas y J. Lombardi (dirs.), Historia general de América Latina, vol. 5 (pp. 513-522). Madrid: Unesco/Trotta.

. (2010). Andrés Bello: la pasión por el orden. 2. ${ }^{\text {a }}$ ed. Santiago: Editorial Universitaria.

. (2015). Los Cuadernos de Londres de Andrés Bello. Boletín de Filología, 50(2), 181-189. 
Kordić, R. (2000-2001). La estabilización del seseo en Chile colonial: un testimonio. Boletín de Filología, 38, 351-360.

. (2011). La Independencia y la estandarización de la lengua hispanoamericana: una mirada desde sus textos. Onomázein, 23, 171-179.

Matus, A. (1991). El español atlántico en textos dialectales chilenos del siglo XIX. En Actas del III Congreso Internacional sobre el español de América (pp. 1039-1052). Valladolid: Junta de Castilla y León. . (1998-1999). Configuración de la base lingüística del español de Chile. Boletín de Filología, 37, 765-780.

Matus, A., Dargham, S. y Samaniego, J. L. (1992). Notas para una historia del español en Chile. En C. Hernández A. (ed.), Historia y presente del español de América (pp. 543-564). Valladolid: Junta de Castilla y León.

Milroy, J. (2007). The ideology of the standard language. En C. Llamas, L. Mullany y P. Stockwell (eds.), The Routledge Companion to Sociolinguistics (pp. 133-139). London \& New York: Routledge.

Moré, B. (2014). Lengua y poder en la obra gramatical de Andrés Bello. Caracas: Fundación Casa Nacional de las Letras Andrés Bello.

Rodríguez, Z. (1875). Diccionario de chilenismos. Santiago: Imprenta El Independiente.

Rojas, D. (2010). Estandarización lingüística y pragmática del diccionario: forma y función de los 'diccionarios de provincialismos' chilenos. Boletín de Filología, 45(1), 209-233.

. (2011). El empleo de los pronombres oblicuos de tercera persona en la etapa formativa del español de Chile (1541- c. 1650). Revista de Humanidades, 24, 141-159.

. (2015). Ideologías y actitudes lingüísticas en el Chile hispanohablante de la segunda mitad del siglo XIX. Tesis doctoral, Universidad de Valladolid.

Rojas, D. y Avilés, T. (2016). Language norms and language use: hypercorrections in the Independence period of Chilean Spanish. Folia Linguistica Historica, 37, 177-204.

Ruiz, C. (2015). Las ideas conservadoras en Chile. Antecedentes históricos. En R. Cristi y C. Ruiz, El pensamiento conservador en Chile. Seis ensayos (pp. 173-187). Santiago: Editorial Universitaria. 
San Martín, A. (2006). Fundamentos para un debate en torno a la aspiración de $h$-proveniente de $f$ - latina en documentos coloniales chilenos. Persona y Sociedad, 20(2), 193-215.

Sotomayor, R. (1866). Formación del diccionario hispano-americano. Anales de la Universidad de Chile, XXVIII(10), 665-681.

Velleman, B. L. (2002). Linguistic anti-academicism and Hispanic community: Sarmiento and Unamuno. En J. del Valle y L. GabrielStheeman (eds.), The Battle over Spanish between 1800 and 20oo. Language ideologies and Hispanic intellectuals (pp. 14-41). London \& New York: Routledge.

Watts, R. J. (2008). Grammar writers in eighteenth-century Britain: A community of practice or a discourse community? En I. Tieken-Boon van Ostade (ed.), Grammars, Grammarians and Grammar-Writing in Eighteenth-Century England (pp. 37-56). Berlin \& New York: Mouton de Gruyter.

. (2012). Language myths. En J. M. Hernández-Campoy y J. C. CondeSilvestre (eds.), The handbook of historical sociolinguistics (pp. 585-606). Malden: Wiley-Blackwell. 